\title{
NUFT USNT Thermal Input Parameters
}

K.H. Lee

September 1, 2000

U.S. Department of Energy

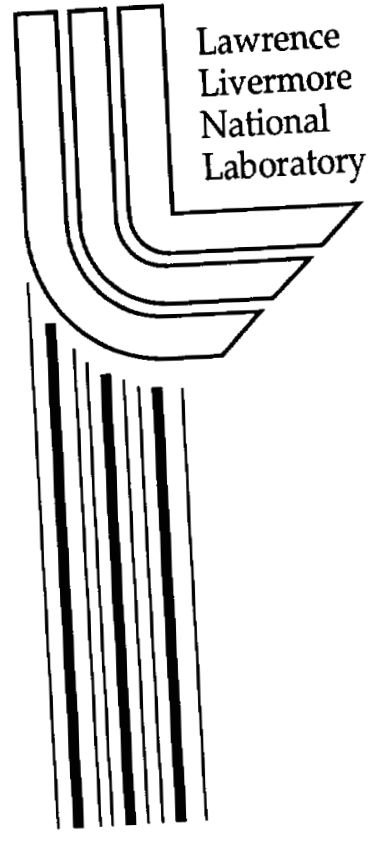




\section{DISCLAIMER}

This document was prepared as an account of work sponsored by an agency of the United States Government. Neither the United States Government nor the University of California nor any of their employees, makes any warranty, express or implied, or assumes any legal liability or responsibility for the accuracy, completeness, or usefulness of any information, apparatus, product, or process disclosed, or represents that its use would not infringe privately owned rights. Reference herein to any specific commercial product, process, or service by trade name, trademark, manufacturer, or otherwise, does not necessarily constitute or imply its endorsement, recommendation, or favoring by the United States Government or the University of California. The views and opinions of authors expressed herein do not necessarily state or reflect those of the United States Government or the University of California, and shall not be used for advertising or product endorsement purposes.

This work was performed under the auspices of the U.S. Department of Energy by the University of California, Lawrence Livermore National Laboratory under Contract No. W-7405-Eng-48.

This report has been reproduced directly from the best available copy.

Available electronically at http://www.doe.gov/bridge

Available for a processing fee to U.S. Department of Energy

and its contractors in paper from

U.S. Department of Energy

Office of Scientific and Technical Information

P.O. Box 62

Oak Ridge, TN 37831-0062

Telephone: (865) 576-8401

Facsimile: (865) 576-5728

E-mail: reports@adonis.osti.gov

Available for the sale to the public from

U.S. Department of Commerce

National Technical Information Service

5285 Port Royal Road

Springfield, VA 22161

Telephone: (800) 553-6847

Facsimile: (703) 605-6900

E-mail: orders@ntis.fedworld.gov

Online ordering: http://www.ntis.gov/ordering.htm

OR

Lawrence Livermore National Laboratory

Technical Information Department's Digital Library

http://www.llnl.gov/tid/Library.html 


\title{
NUFT USNT Thermal Input Parameters
}

\author{
Kenrick H. Lee \\ September, 00
}

This document describes the thermal input parameters required to run the USNT module of the NUFT code. The USNT module handles multi-component transport of multiple fluid phases and heat through porous and fractured media. The thermal input parameters required to model the heat transport by conduction, convection, and radiation are summarized, and the relevant mixing rules outlined. This is followed by a table that describes the thermal input parameters in a typical NUFT input file used for YMP thermal-hydrological calculations.

Most of the material presented here is summarized from the user's manual of the USNT module of NUFT (Nitao, 2000).

\section{Thermal Conductivity}

The code requires the effective bulk thermal conductivity of materials to compute the transport of heat by conduction. The thermal conductivity is a constitutive coefficient that must be measured experimentally as a function of fluid phase saturation. The user must input the bulk thermal conductivity, in the rocktab input block, at full saturation for each of the fluid phases in the model. For typical Yucca Mountain calculations, a liquid phase and a gas phase are present. If the thermal conductivity varies significantly with temperature over the range of temperatures modeled, then the temperature-dependence can also be supplied as part of the input.

Two options are available for typical Yucca Mountain thermal hydrology (TH) problems, where the porous medium contains a maximum of two phases, liquid and gas ( $\alpha=$ liquid, gas). In the first option the total bulk thermal conductivity is calculated using a linear weighting of fluid phase saturation over NP phases

$$
k^{\text {bulk }}=k^{d r y}+\sum_{\alpha=1}^{N P} S_{\alpha}\left(k_{\alpha}^{s a t}-k^{d r y}\right)
$$

where $S_{\alpha}$ is the saturation of fluid phase $\alpha$, and the input parameters are

$\mathbf{k}^{\text {dry }}$ bulk thermal conductivity of the porous medium with no fluid in pores (W/m-C)

$\mathrm{k}_{\alpha}^{\text {sat }}$ bulk thermal conductivity of the porous medium saturated by phase $\alpha(\mathrm{W} / \mathrm{m}-\mathrm{C})$.

This equation represents the most general form for specifying the bulk thermal conductivity, and applies to the case of a porous medium with multiple fluid phases as well as a porous medium with evacuated pores (no fluids). When there is at least one fluid in the pores, $\mathrm{k}^{\text {bulk }}$ is independent of the term $k^{\text {dry }}$. In typical Yucca Mountain TH calculations, with liquid and gas phases $(\alpha=1, g)$, the required input parameters are $\mathrm{k}^{\mathrm{dry}}, \mathrm{k}^{\mathrm{sat}}{ }_{1}$, and $\mathrm{k}^{\mathrm{sat}}{ }_{\mathrm{g}}$, but $\mathrm{k}^{\mathrm{dry}}$ is not used and therefore does not need to be specified accurately. However, NUFT still requires that some value of $k^{\text {dry }}$ be specified.

The second option is a constant thermal conductivity independent of fluid-phase saturation. The user can also optionally use temperature dependent thermal conductivity with each of the two 
options given above. This is achieved by specifying a temperature dependent factor as a piecewise linear table. The thermal conductivity used in numerical calculations is obtained by multiplying the value from option one or two by the supplied factor.

\section{Specific Heat of Dry Solids}

Solution of the energy balance equation also requires specific heat of the solids and fluids that comprise the bulk porous medium. The specific heat of dry solids $(\mathrm{J} / \mathrm{kg}-\mathrm{C})$ is required in the rocktab block of the input file. This is the specific heat at constant pressure, $\mathrm{c}_{\mathrm{p}}$, and not the specific heat at constant volume, $\mathrm{c}_{\mathrm{v}}$.

\section{Heat Content of Fluids}

Parameters required to calculate the heat content of fluid components are specified in the compprop block of the input file, and the mixing method used to compute the heat content of the phase is specified in phaseprop. The specific enthalpy, $\mathrm{H}(\mathrm{J} / \mathrm{kg})$, of each chemical component is calculated using one of five options.

1. Constant value

Input a value of $\mathrm{H}$ for constant specific enthalpy $(\mathrm{J} / \mathrm{kg})$

2. Calculate $\mathrm{H}$ from the formula

$H=c_{p} *\left(T-T_{r e f}\right)+H v$

Input $\mathrm{c}_{\mathrm{p}}$ : specific heat at constant pressure $(\mathrm{J} / \mathrm{kg}-\mathrm{C})$

$\mathrm{T}_{\text {ref }}$ : reference temperature $(\mathrm{C})$

$\mathrm{H}_{\mathrm{v}}$ : reference enthalpy $(\mathrm{J} / \mathrm{kg})$.

3. Calculate $\mathrm{H}$ from the formula

$$
H=C_{p} *(T-\text { Tref })+a\left(T-T_{c}\right)^{b}
$$

Input $c_{p}:$ specific heat at constant pressure $(\mathrm{J} / \mathrm{kg}-\mathrm{C})$

$\mathrm{T}_{\mathrm{ref}}:$ reference temperature $(\mathrm{C})$

$\mathrm{T}_{\mathrm{c}}$ : critical temperature $(\mathrm{C})$

a: parameter

b: parameter

4. By specifying this option, the code uses the partial enthalpy of water in a pure aqueous phase, calculated from the steam tables; can be used, as an approximation, for dilute solutions.

5. By specifying this option, the code uses the partial enthalpy water in a pure water vapor phase; can be used, as an approximation, for water vapor in ideal gas mixtures.

Specific enthalpy of the phase is specified in the phaseprop input block of the code using one of the two options.

1. Input a constant specific enthalpy $\mathrm{H}(\mathrm{J} / \mathrm{kg})$

2. Select linear mixing of $\gamma$ component partial enthalpies, $H^{\gamma}$, in $\alpha$ phase

$$
H_{\alpha}=\sum_{\gamma} X_{\alpha}^{\gamma} H_{\alpha}^{\gamma}
$$

where $\mathrm{X}^{\gamma}$ is the mass fraction of the $\gamma$ component in the $\alpha$ phase.

\section{Solid and Fluid Density}

The solid grain density $\left(\mathrm{kg} / \mathrm{m}^{3}\right)$ of each material is required input in the rocktab input block. The molecular mass ( $\mathrm{g} / \mathrm{mole}$ ) of each component is required in compprop. 
Parameters specifying the partial mass density of each component must be supplied in compprop. The density $\rho$, is calculated from the following formula based on constant compressibility.

$$
\rho=\rho_{0} \exp \left[c\left(p-p_{0}\right)\right]
$$

The input parameters are

$$
\begin{array}{ll}
\rho_{0} & \text { reference density }(\mathrm{kg} / \mathrm{m} 3) \\
\mathrm{p}_{0} & \text { reference pressure }(\mathrm{Pa}) \\
\mathrm{c} & \text { compressibility }(1 / \mathrm{Pa})
\end{array}
$$

The user also has the option to select the partial mass density of pure liquid water calculated from the steam table; this is an approximation for a water component in a dilute aqueous phase.

The user is offered four options for calculating the phase mass density from the partial mass density of each component

1. Calculate the density, $\rho$, based on linear volumetric mixing

$$
\frac{1}{\rho}=\sum_{\gamma} \frac{X^{\gamma}}{\rho^{\gamma}}
$$

where $\mathrm{X}^{\gamma}$ and $\rho^{\gamma}$ are the mass fraction and partial mass density of the $\gamma$ component, respectively.

2. Phase density of the gas phase based on the ideal gas law. If there is a component called water, a "Z-factor" is used to correct the water vapor density from steam tables.

3. Phase density of the gas phase based on the ideal gas law.

4. Density of pure liquid water phase; can be used as an approximation for a dilute aqueous phase.

\section{Equilibrium Partitioning}

The user must supply parameters that specify the equilibrium partitioning of components between fluid phases. A convenient reference phase must be chosen for each component, and the partitioning coefficient, $\mathrm{K}_{\mathrm{eq}}$, for that reference phase set to unity. All other coefficients are then defined with respect to the reference phase. $K_{\mathrm{eq}}$ for a component in phase $\alpha$ is equal to the mole fraction of the component in the $\alpha$ phase divided by the mole fraction of the component in the reference phase. The code accepts four options for specifying $\mathrm{K}_{\mathrm{eq}}$ in thermal models:

1. Constant coefficient (mole/mole)

2. $K e q=(A+p g * B+C / p g) * \exp (-D / T K e l v)$

where $\mathrm{A}, \mathrm{B}, \mathrm{C}$, and D are user-specified parameters, $\mathrm{pg}$ is the gas pressure, and Tkelv is the 
temperature in Kelvin. Parameters A, B, and D are optional and default to zero. This formulation assumes that the liquid phase is the reference phase.

3. Select coefficient for TCE in gas phase, KeqTCESolute. Assumes that the liquid phase is the reference phase.

4. Select coefficient for water vapor in the gas phase, KeqWatVapor. Assumes that the liquid phase is the reference phase.

\section{Source Term}

Source terms, given in the srctab block of the input file, specify a mass or heat generation rate in a cell or range of cells, through a table of source fluxes at specified times. Component fluxes may be specified (including the energy component) using compflux, or phase fluxes using phaseflux. For a heat source, heating power (W) is tabulated versus time. Whenever a mass flux is specified an enthalpy table must be supplied to give the heat content of the components. The table gives specific partial enthalpies $(\mathrm{J} / \mathrm{kg})$ of the component as a function of time. Linear interpolation is used to calculate enthalpy between time values.

\section{Thermal Radiation}

The energy balance equation in NUFT handles the transfer of heat between elements by thermal radiation. This option is applied to model radiative heat transfer across surfaces such as waste package to drift wall, waste package to waste package, and drift wall to drift wall. The radiation flux, $\mathrm{q}_{\mathrm{r}}$, between two surfaces, 1 and 2 , is given by

$$
q_{r}=A_{1} C\left[T_{1}^{4}-T_{2}^{4}\right]
$$

where $A_{1}$ is the surface area of face $1, C$ is a user-specified coefficient, and $T_{1}$ and $T_{2}$ are the absolute temperatures of surface 1 and surface 2 , respectively. The user is expected to calculate $\mathrm{C}$ from

$C=F \varepsilon \sigma$,

where $\mathrm{F}$ is a view factor that depends on the geometry of the system, $\varepsilon$ is the emissivity, and $\sigma$ is the Stefan-Boltzmann constant. Any pair of surfaces across which radiative heat transfer is to be modeled, must have $\mathrm{A}_{1}$ and $\mathrm{C}$ specified in the input file. For large numbers of radiation connections, the preprocessor RADPRO may be used to help the user specify connections and calculate coefficients.

\section{DKM and ECM Models}

The Dual Permeability Model (DKM) and the Equivalent Continuum Model (ECM) are two models commonly used to mathematically represent fracture-matrix interaction in $\mathrm{TH}$ calculations for Yucca Mountain. Each of these two models requires separate material input parameters, including thermal parameters, for the matrix and fractures. For example, a DKM input file must include separate thermal conductivity parameters for the rock matrix and the fractures. 


\section{Examples of NUFT Thermal Input}

The following table describes the thermal input parameters typically used for YMP thermalhydrological (TH) calculations with the NUFT code. I took one of the main input files used in TH calculations for the Large Block Test (LBT), highlighted the thermal input parameters, and used the table to describe usage of the parameters in NUFT input. Note that material properties are given for several materials, but the thermal parameters for just one material needs to be highlighted and described here. The LBT input file, lbt_AMR_ds, is shown in Attachment 1. The file includes another file, vt-rmsew.pkg, which in turn, includes the file vtough.pkg. vtough.pkg has some thermal input parameters, and is therefore shown in Attachment 2. These included files specify numerical settings, chemical components, and phases for typical YMP TH problems. Thermal parameters and input options selected in vtough.pkg are also highlighted and addressed in the table. The NUFT thermal radiation option was not used in LBT calculations addressed here. However, an example of radiation input parameters is included in the table, since radiation is frequently used in our YMP TH calculations.

\section{NUFT Thermal Input Parameters}

\begin{tabular}{|c|c|c|}
\hline $\begin{array}{l}\text { Main Data } \\
\text { Block }\end{array}$ & Input Format and Parameters & Description of Input \\
\hline Modprop & $\begin{array}{l}\text { (modprop } \\
\text { (tcond (range "UT*") } \\
\qquad \begin{array}{llll}(0.0 & 1.0 & 1.08 \mathrm{e} 7 & 1.0 \\
(1.081 \mathrm{e} 7 & .527 & 1 \mathrm{e} 30 & .527))\end{array}\end{array}$ & $\begin{array}{l}\text { Modprop is an optional command to modify } \\
\text { the thermal conductivity for a range of cells, } \\
\text { specified in rocktab, by a time-dependent } \\
\text { factor. Linear interpolation used between } \\
\text { times in table. }\end{array}$ \\
\hline Rocktab & $\begin{array}{l}\text { (rocktab } \\
\quad(\mathrm{m} \text {-tsw34 } \\
\quad(\text { solid-density } 2.505 \mathrm{e}+03) \ldots\end{array}$ & $\begin{array}{l}\text { Grain density of solids for material m-tsw34 } \\
\text { set to } 2505 \mathrm{~kg} / \mathrm{m}^{3}\end{array}$ \\
\hline Rocktab & $\begin{array}{l}\text { (rocktab } \\
\quad(\mathrm{m}-\mathrm{tsw} 34 \\
\quad(\mathrm{Cp} 9.480 \mathrm{e}+02) \ldots\end{array}$ & $\begin{array}{l}\text { Specific heat for material m-tsw34 set to } 948 \\
\mathrm{~J} / \mathrm{kg}-\mathrm{C}\end{array}$ \\
\hline Rocktab & $\begin{array}{l}\text { (rocktab } \\
\text { (m-tsw34 } \\
\quad \text { (tcond tcondLin (solid 1.544) } \\
\quad \text { (liquid } 2.307)(\text { gas } 1.544) \ldots\end{array}$ & $\begin{array}{l}\text { Bulk thermal conductivity of m-tsw } 34 \text { is } \\
2.307 \mathrm{~W} / \mathrm{m}-\mathrm{C} \text { saturated with liquid, and } \\
1.544 \mathrm{~W} / \mathrm{m}-\mathrm{C} \text { saturated with gas. Thermal } \\
\text { conductivity at other saturations obtained by } \\
\text { linear interpolation. The thermal } \\
\text { conductivity value for solid is not used by } \\
\text { the code when fluids are present, but is } \\
\text { required in the input; can use any numerical } \\
\text { value. }\end{array}$ \\
\hline Srctab & $\begin{array}{l}\text { (srctab } \\
\text { (compflux } \\
\text { (name heat1 } \\
\text { (range "E1.m*") } \\
\text { (table } 0.0 \quad 111.98 \quad 15840 \quad 339.20)\end{array}$ & $\begin{array}{l}\text { Specification of a time-varying heat source } \\
\text { from a specified range of elements (El.m*). } \\
\text { Heat output at different times is specified in } \\
\text { table; linear interpolation used to obtain heat } \\
\text { output at times between table values. }\end{array}$ \\
\hline
\end{tabular}




\begin{tabular}{|c|c|c|}
\hline & (allocate-by-volume)... & $\begin{array}{l}\text { Allocate-by-volume instructs NUFT to divide } \\
\text { the total heat output from source elements in } \\
\text { proportion to element volume. The } \\
\text { compflux set name, heat } 1 \text {, is used for data } \\
\text { output options. }\end{array}$ \\
\hline Init-eqts & $\begin{array}{l}\text { (init-eqts } \\
\quad \text { (thermal)... }\end{array}$ & $\begin{array}{l}\text { Energy balance equation is solved when set } \\
\text { to thermal; the energy balance equation is } \\
\text { not solved when set to isothermal. }\end{array}$ \\
\hline Phaseprop & $\begin{array}{l}\text { (phaseprop } \\
\text { (liquid } \\
\quad \text { (rhoP rhoPLiqWat)... }\end{array}$ & $\begin{array}{l}\text { The rhoP option rhoPLiqWat selects the } \\
\text { density of pure liquid water as the density of } \\
\text { the aqueous phase; this is used as an } \\
\text { approximation for a dilute aqueous phase. }\end{array}$ \\
\hline Phaseprop & $\begin{array}{l}\text { (phaseprop } \\
\text { (liquid } \\
\quad \text { (enthP enthPLinearMix)... }\end{array}$ & $\begin{array}{l}\text { The enthP option enthPLinearMix selects } \\
\text { linear mixing of the component partial } \\
\text { enthalpies to determine the aqueous phase } \\
\text { enthalpy. }\end{array}$ \\
\hline Phaseprop & $\begin{array}{l}\text { (phaseprop } \\
\text { (liquid } \\
\quad \text { (pcTemFac watPcTemFac)... }\end{array}$ & $\begin{array}{l}\text { The pcTemFac keyword activates NUFT } \\
\text { temperature-dependent capillary pressure. } \\
\text { With the watPcTemFac option, the capillary } \\
\text { pressure is multiplied by a temperature- } \\
\text { dependent factor based on the capillary } \\
\text { pressure of water. }\end{array}$ \\
\hline Phaseprop & $\begin{array}{l}\text { (phaseprop } \\
\quad \text { (gas } \\
\quad(\text { rhoP rhoPZFacStm)... }\end{array}$ & $\begin{array}{l}\text { With the rhoP option rhoPZFacStm, phase } \\
\text { density of the gas phase is based on the ideal } \\
\text { gas law. If there is a component called } \\
\text { water, a "Z-factor" is used from the steam } \\
\text { tables to correct for the water vapor density. }\end{array}$ \\
\hline Phaseprop & $\begin{array}{l}\text { (phaseprop } \\
\text { (gas } \\
\quad(\text { enthP enthPLinearMix)... }\end{array}$ & $\begin{array}{l}\text { The enthP option enthPLinearMix selects } \\
\text { linear mixing of the component partial } \\
\text { enthalpies to determine the gas phase } \\
\text { enthalpy. }\end{array}$ \\
\hline Compprop & $\begin{array}{l}\text { (compprop } \\
\text { (water } \\
\quad(\text { intrinsic (MoleWt 18.0)) } \\
\quad(\text { gas } \\
\quad(\text { enthC enthCWatVap))... }\end{array}$ & $\begin{array}{l}\text { The enthC option enthCWat Vap selects the } \\
\text { partial enthalpy of water in a pure water } \\
\text { vapor phase; used as an approximation, for } \\
\text { water vapor in ideal gas mixtures. }\end{array}$ \\
\hline Compprop & $\begin{array}{l}\text { (compprop } \\
\text { (water } \\
\quad \text { (intrinsic (MoleWt 18.0)) } \\
\quad \text { (liquid } \\
\quad(\text { enthC enthCLiqWat))... }\end{array}$ & $\begin{array}{l}\text { The enthC option enthCLiqWat selects the } \\
\text { partial enthalpy of water component in a } \\
\text { pure aqueous, calculated from steam tables; } \\
\text { used as an approximation for dilute } \\
\text { solutions. }\end{array}$ \\
\hline Compprop & $\begin{array}{l}\text { (compprop } \\
\text { (water } \\
\quad \text { (intrinsic (MoleWt 18.0)) } \\
\text { (liquid }\end{array}$ & $\begin{array}{l}\text { The rhoC option rhoCLiqWat selects the } \\
\text { partial mass density of a pure water phase, } \\
\text { calculated from the steam tables; an } \\
\text { approximation for water component in dilute }\end{array}$ \\
\hline
\end{tabular}




\begin{tabular}{|c|c|c|}
\hline & $($ rhoC rhoCLiqWat))... & aqueous phase. \\
\hline Compprop & $\begin{array}{l}\text { (compprop } \\
\quad \text { (air } \\
\quad(\text { intrinsic }(\text { MoleWt 29.0)) } \\
\quad(\text { gas } \\
\quad(\text { enthC enthCConstCp }(\mathrm{Cp} \\
\text { 1009.0) }(\text { Tref } 0.0)(\mathrm{Hv} 0.0))) \ldots\end{array}$ & $\begin{array}{l}\text { The enthC option enthCConstCp as used } \\
\text { here calculates the specific enthalpy of } \\
\text { component air from the formula } \\
H=C_{p} *(T-T r e f)+H v \\
\text { where } C_{p} \text { is the specific heat }(\mathrm{J} / \mathrm{kg}-\mathrm{C}) \text {, Tref the } \\
\text { reference temperature }(C) \text {, and } H_{\mathrm{v}} \text { the reference } \\
\text { enthalpy }(\mathrm{J} / \mathrm{kg}) \text {. }\end{array}$ \\
\hline Compprop & $\begin{array}{l}\text { (compprop } \\
\text { (air } \\
\quad \text { (intrinsic (MoleWt 29.0)) } \\
\quad \text { (liquid } \\
\quad \text { (rhoC rhoCLiqWat))... }\end{array}$ & $\begin{array}{l}\text { The rhoC option rhoCLiqWat gives a } \\
\text { fictitious value for the partial mass density of } \\
\text { air in the aqueous phase. This value is not } \\
\text { used in PVT calculations because } \\
\text { rhoPZFacStm does not use it; only used in } \\
\text { chemical potential calculations. }\end{array}$ \\
\hline Genmsh & 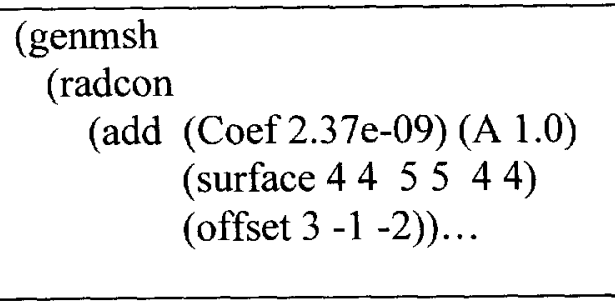 & $\begin{array}{l}\text { The radcon data block within genmsh adds } \\
\text { radiation connections between pairs of } \\
\text { elements. Here the elements }(4,5,4) \text { and } \\
(7,4,2) \text { are connected with a coefficient of } \\
2.37 \mathrm{e}-09 \text {. See the NUFT USNT User's } \\
\text { Manual for more details. }\end{array}$ \\
\hline
\end{tabular}

\section{References}

Nitao, J.J., User's manual for the USNT Module of the NUFT Code, Version 3.0, Lawrence Livermore National Laboratory, Livermore, CA, UCRL-MA-130653 Rev. 2., 2000.

\section{Attachment 1: Example NUFT Input File}

\footnotetext{
; I IBT AMR Calculations using basecase driftscale data
} 


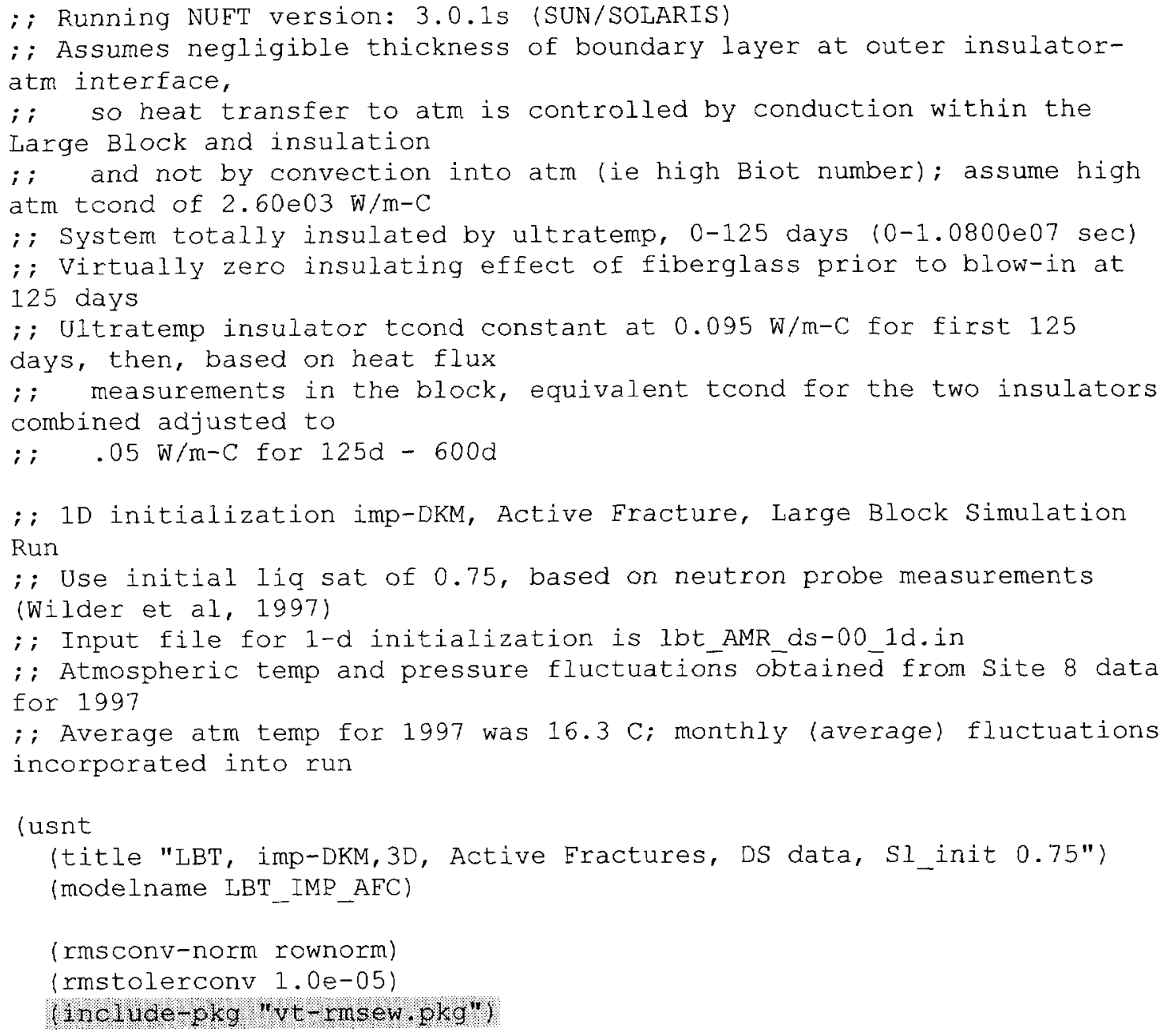


; i Ultratemp insulator tcond constant at $0.095 \mathrm{~W} / \mathrm{m}-\mathrm{C}$ for first 125

days, then, based on heat flux

; measurements in the block, equivalent tcond for the two insulators combined adjusted to

; $\quad .05 \mathrm{~W} / \mathrm{m}-\mathrm{C}$ for $125 \mathrm{~d}-600 \mathrm{~d}$

110010100

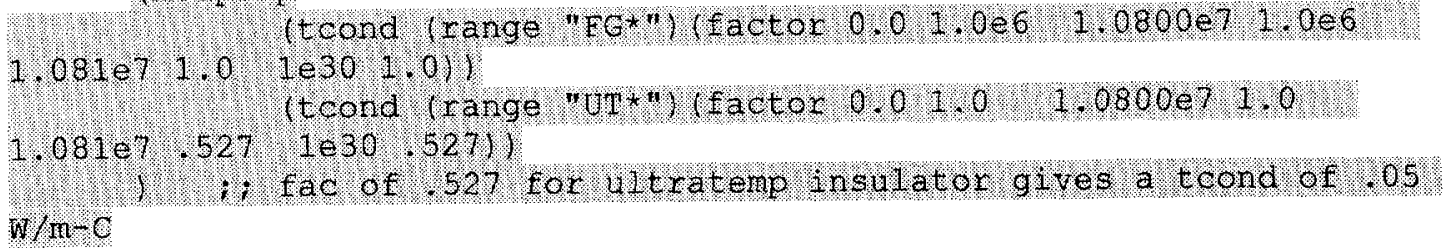

; ;

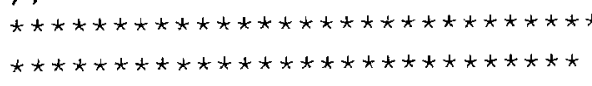

loutput

(extool (continuum $\mathrm{m}$ )

(file-ext ".m.ext") (range "*.m*")

(variables S.liquid T P)

; $\quad$ (variables logloko s.liquid)

(outtimes 0100 ld 5 d 10d 15d 20d 543.5h 575.5h 25d 30d

$40 \mathrm{~d} 42 \mathrm{~d} 43 \mathrm{~d} 46 \mathrm{~d} 50 \mathrm{~d} 55 \mathrm{~d} 60 \mathrm{~d}$

$100 \mathrm{~d} 105 \mathrm{~d}$

$182.625 \mathrm{~d} 192 \mathrm{~d}$

$64 d 66 d 70 d 73 d 75 d 77 d 80 d 85 d 90 d 95 d$

$110 \mathrm{~d} 115 \mathrm{~d} 120 \mathrm{~d} 125 \mathrm{~d} 127 \mathrm{~d} 130 \mathrm{~d} 133 \mathrm{~d}$

$135 \mathrm{~d} 140 \mathrm{~d} 145 \mathrm{~d} 150 \mathrm{~d} 154.45 \mathrm{~d} 160 \mathrm{~d} 169 \mathrm{~d} 175 \mathrm{~d}$

$200 d 222 d 225 d 230 d 240 d 250 d 275 d 279 d 280 d$

$282 d 290 d$

$300 d$ 320d $340 d$ 350d 365.25d 370d 375d 376d $377 d$

$380 \mathrm{~d} 385 \mathrm{~d} 390 \mathrm{~d} 400 \mathrm{~d} 410 \mathrm{~d} 425 \mathrm{~d} 450 \mathrm{~d} 475 \mathrm{~d} 500 \mathrm{~d} 550 \mathrm{~d}$

600 d)

)

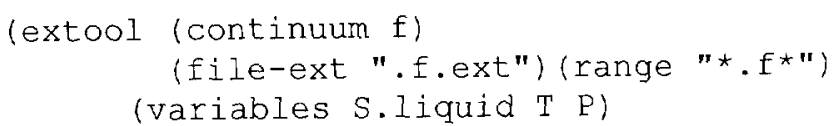

couttimes $01001 \mathrm{~d} 5 \mathrm{~d} 10 \mathrm{~d} 15 \mathrm{~d} 20 \mathrm{~d} 543.5 \mathrm{~h} 575.5 \mathrm{~h} \mathrm{25d} \mathrm{30d}$

$40 \mathrm{~d} 42 \mathrm{~d} 43 \mathrm{~d} 46 \mathrm{~d} 50 \mathrm{~d} 55 \mathrm{~d} 60 \mathrm{~d}$

$100 \mathrm{~d} 105 \mathrm{~d}$

$182.625 \mathrm{~d} 192 \mathrm{~d}$

$282 d 290 d$

$64 d 66 d 70 d 73 d 75 d 77 d 80 d 85 d$ 90d 95d

$110 \mathrm{~d} 115 \mathrm{~d} 120 \mathrm{~d} 125 \mathrm{~d} 127 \mathrm{~d} 130 \mathrm{~d} 133 \mathrm{~d}$

$135 \mathrm{~d} 140 \mathrm{~d} 145 \mathrm{~d} 150 \mathrm{~d} 154.45 \mathrm{~d} 160 \mathrm{~d} 169 \mathrm{~d} 175 \mathrm{~d}$

$200 d 222 d 225 d 230 d 240 d 250 d 275 d 279 d 280 d$

$300 d$ 320d 340d 350d 365.25d 370d 375d 376d 377d

$380 d$ 385d 390d 400d 410d 425d 450d 475d 500d 550d

$600 d)$ 


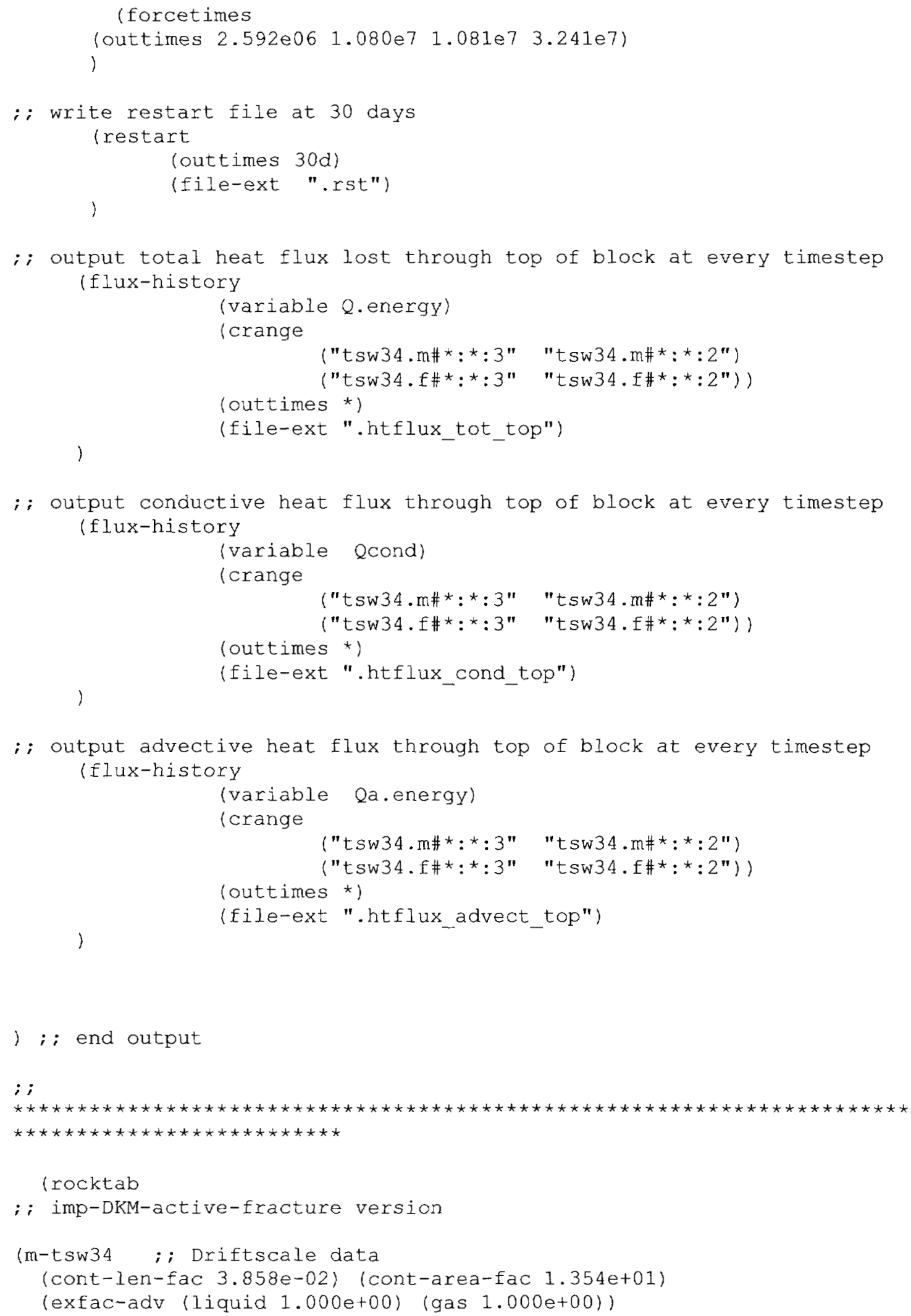




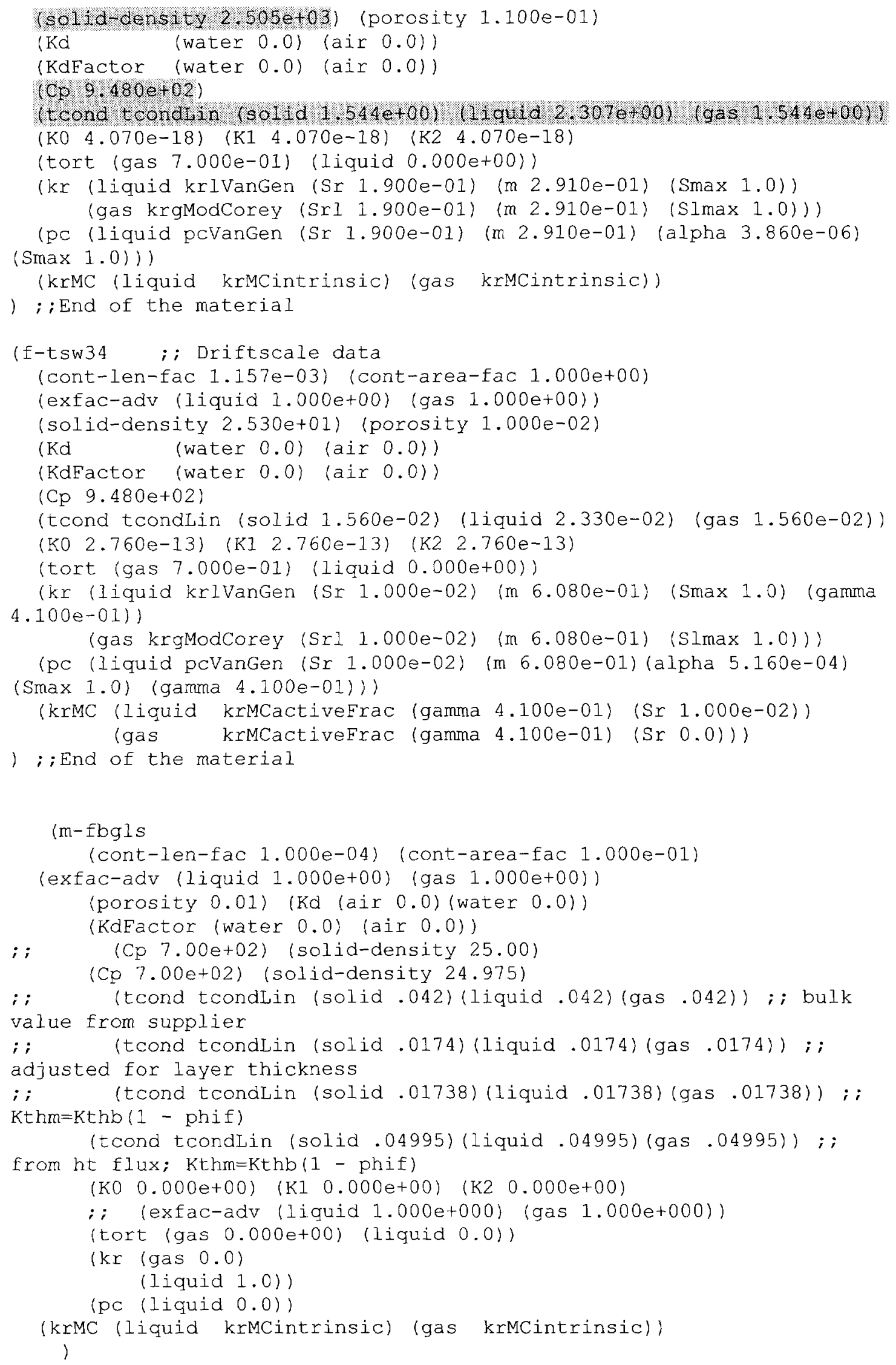




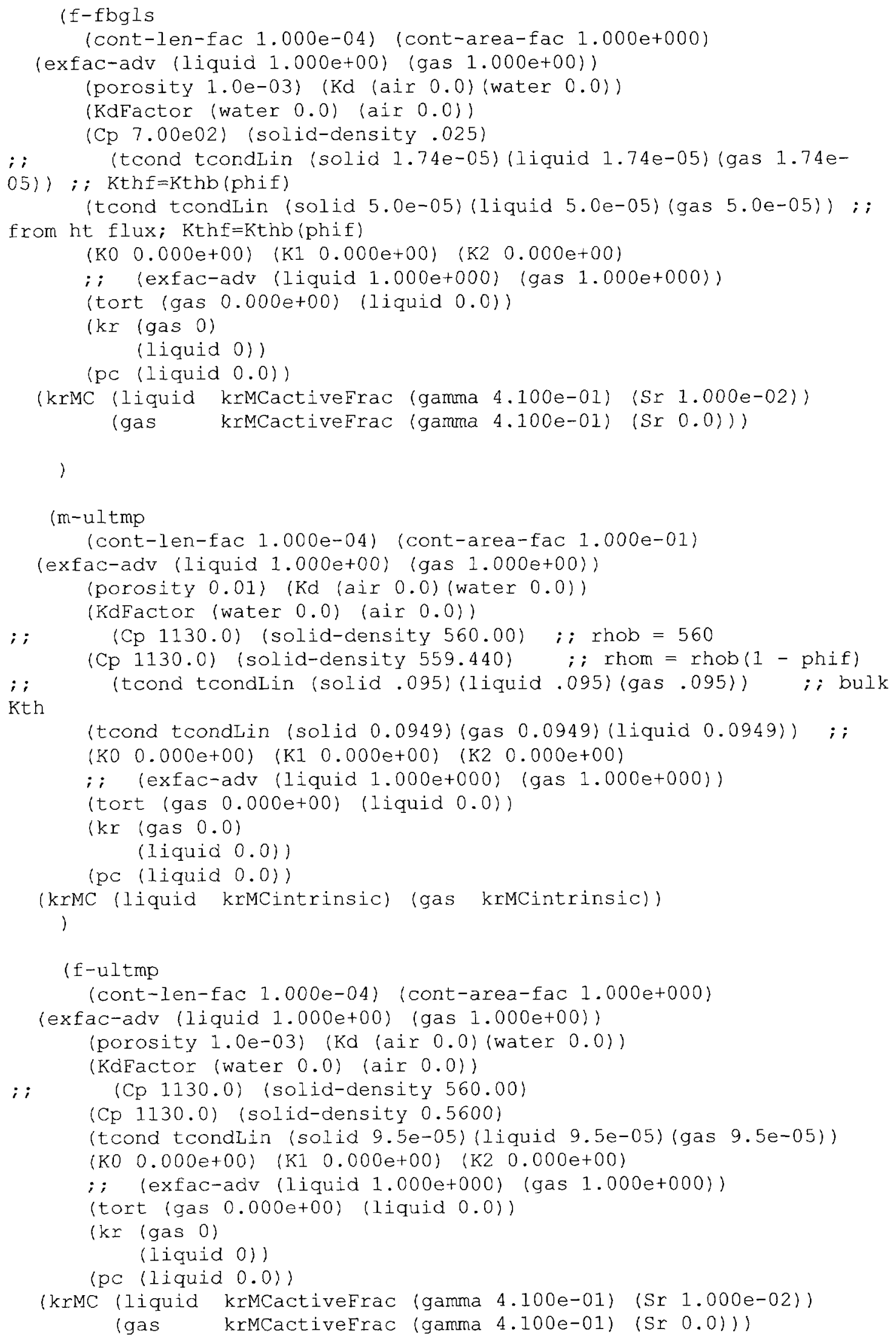




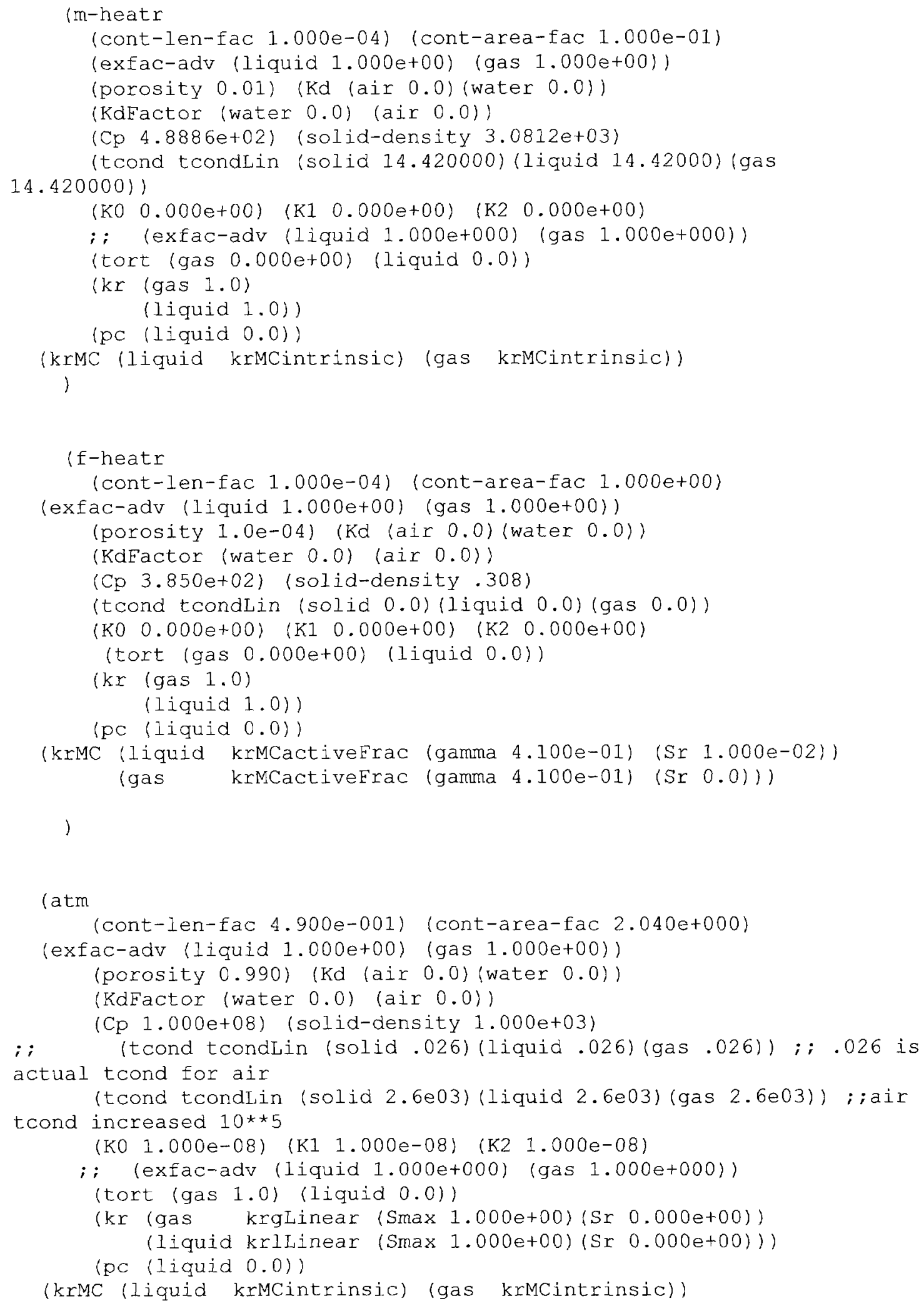




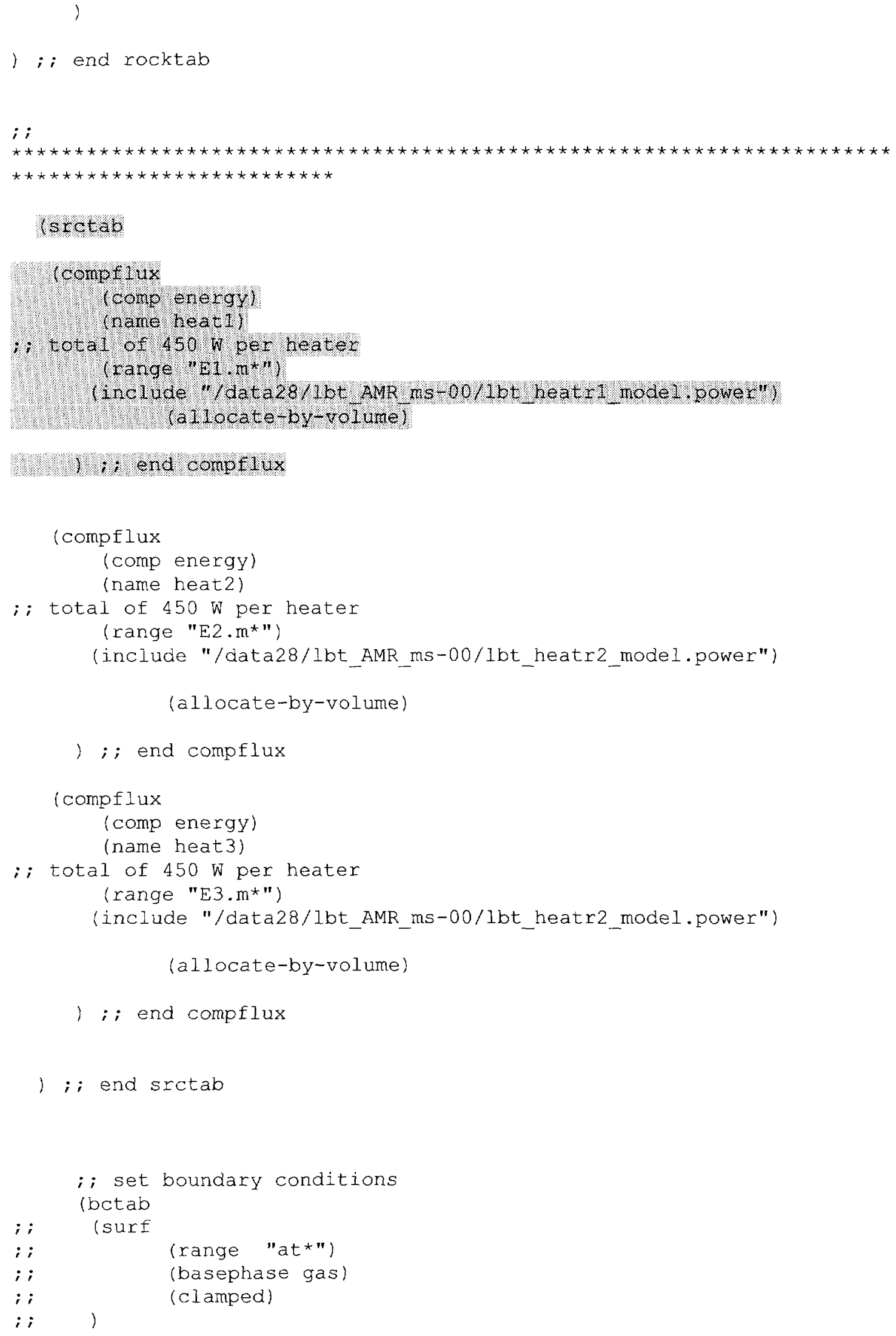


tropbc

$$
\begin{aligned}
& \text { (range "at1*") } \\
& \text { (basephase gas) } \\
& \text { (tables }
\end{aligned}
$$$$
\text { (S.liquid } 0.0 \quad 0.0 \quad 1.0 e 30 \quad 0.0 \text { ) }
$$

(P

$$
0.0 .886947 e 5 \quad 1.0 e 30 \quad .886947 e 5)
$$

(X.air

00/lbt_topT_Xa.table")

$$
\text { (include "/data28/lbt_AMR_ms- }
$$

( $\mathrm{T}$

(include "/data28/lbt AMR ms-

00/lbt_topT_bc.table") ; $0.80 \mathrm{RH}$ at top bc

)

)

)

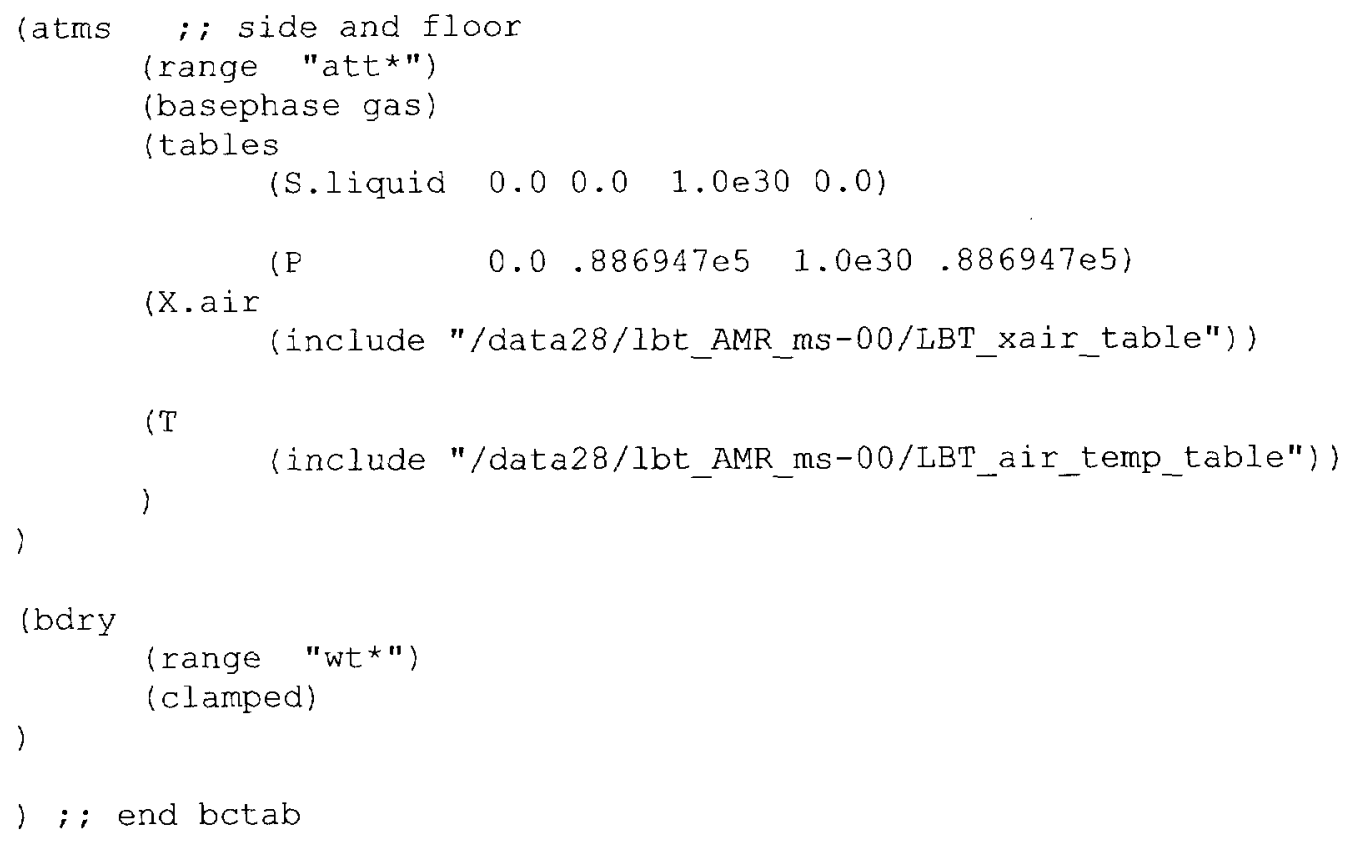




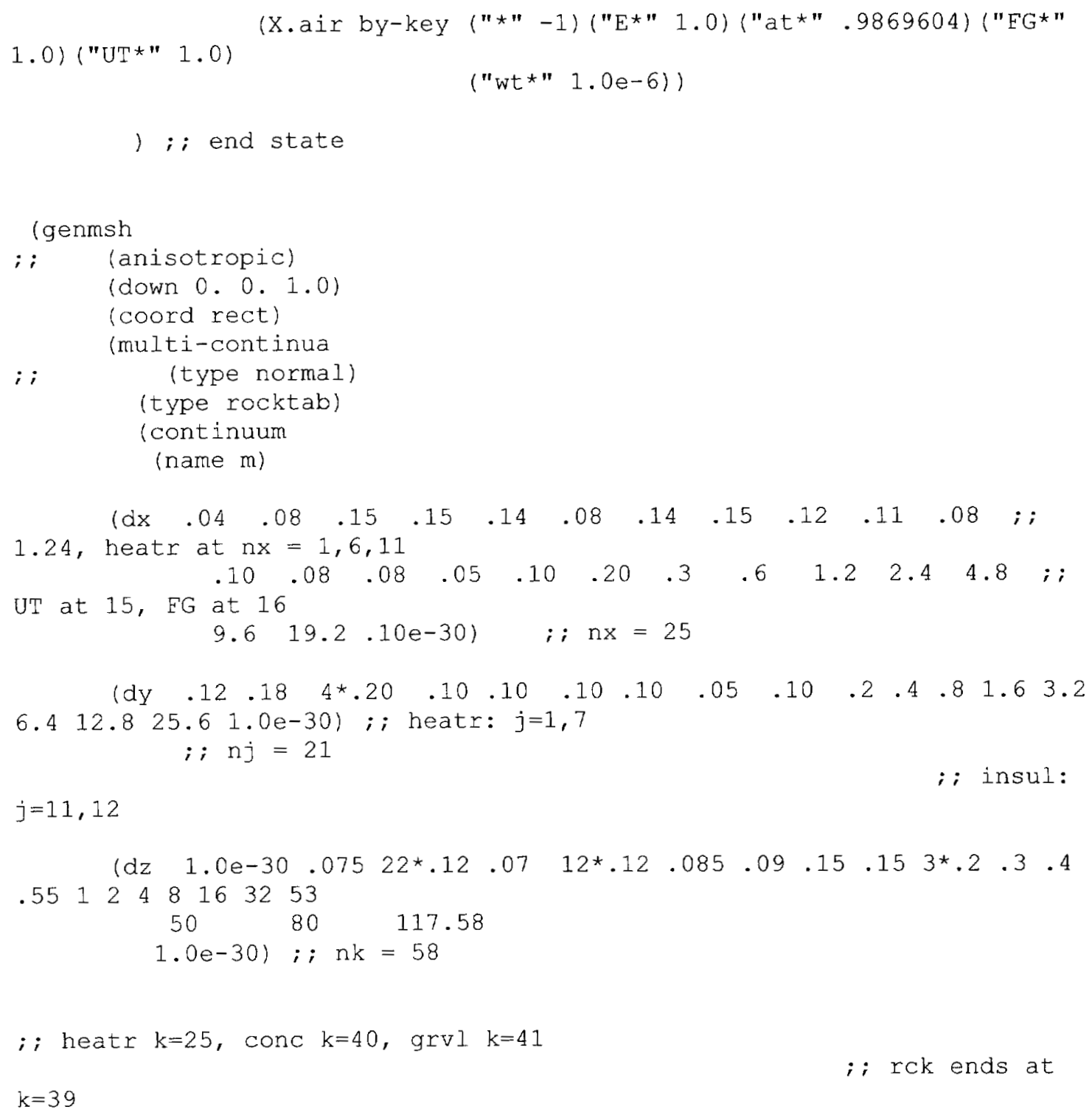




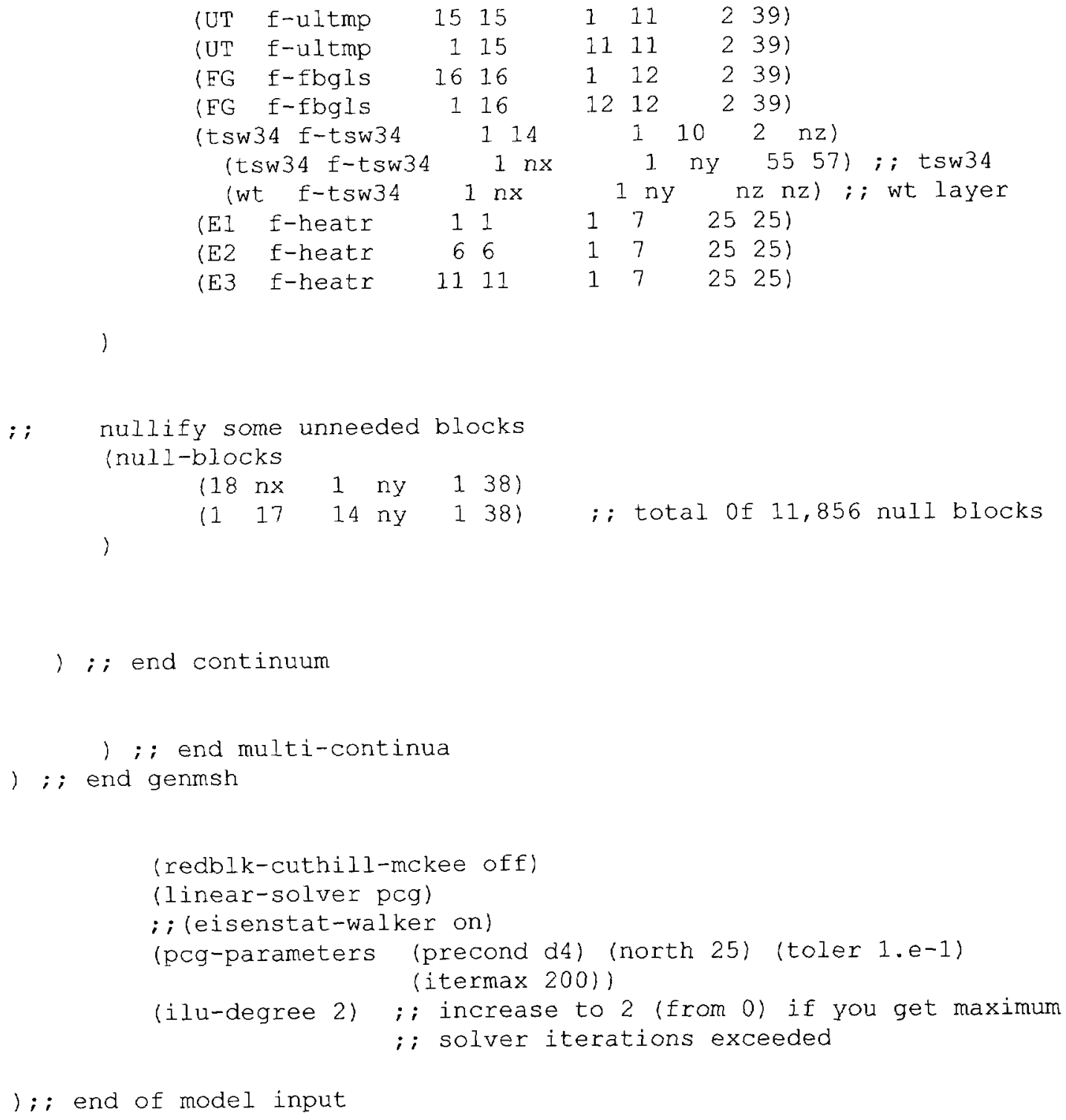

); ; end of model input

Attachment 2: Included Input File vtough.pkg

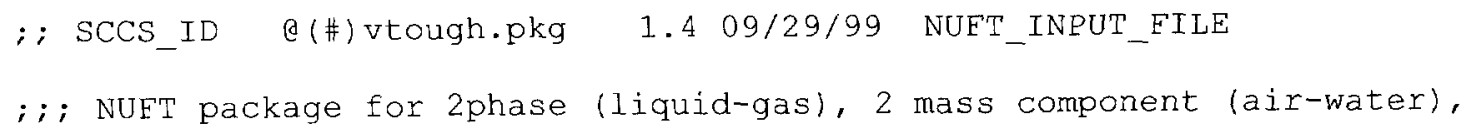




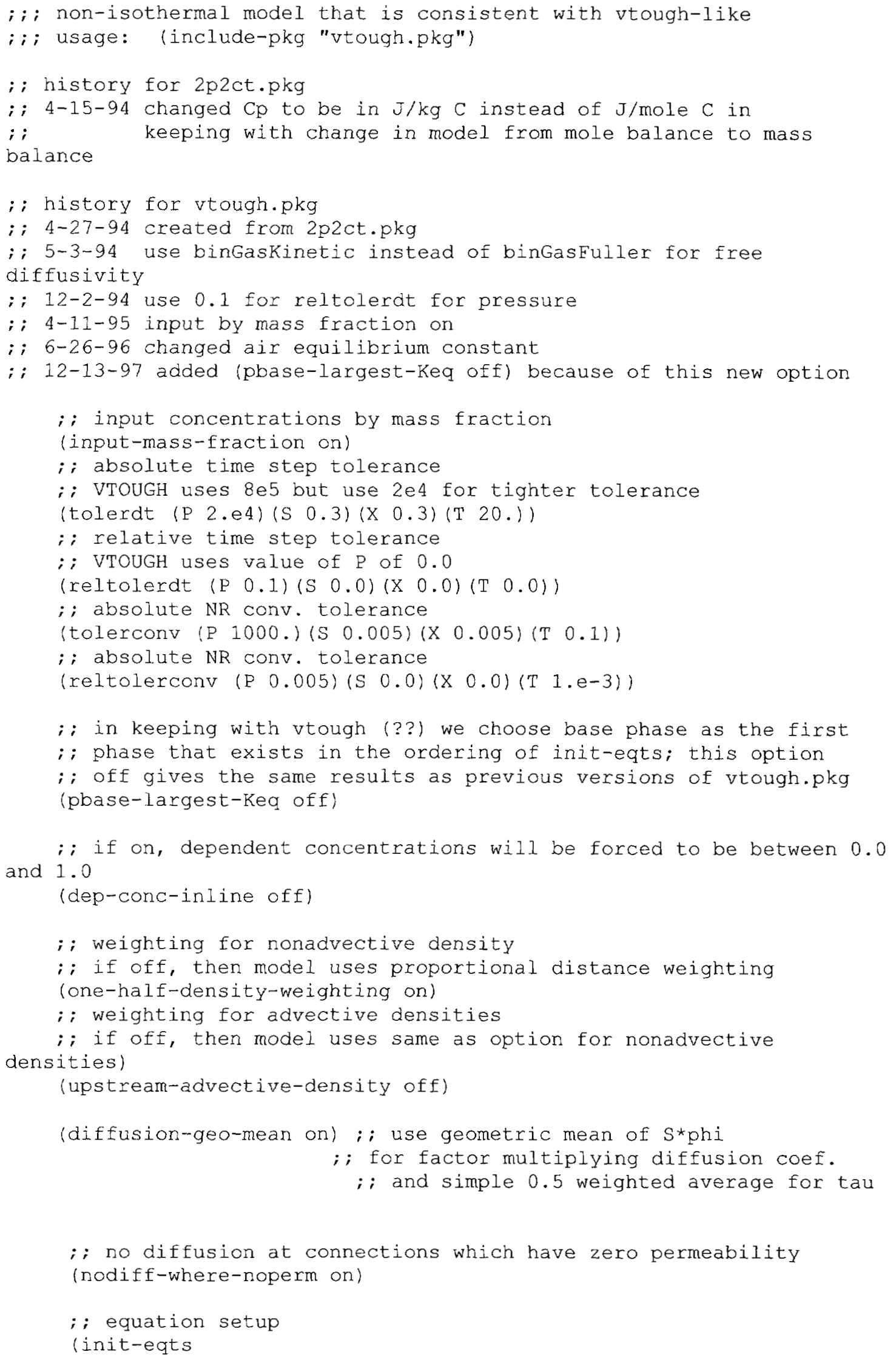




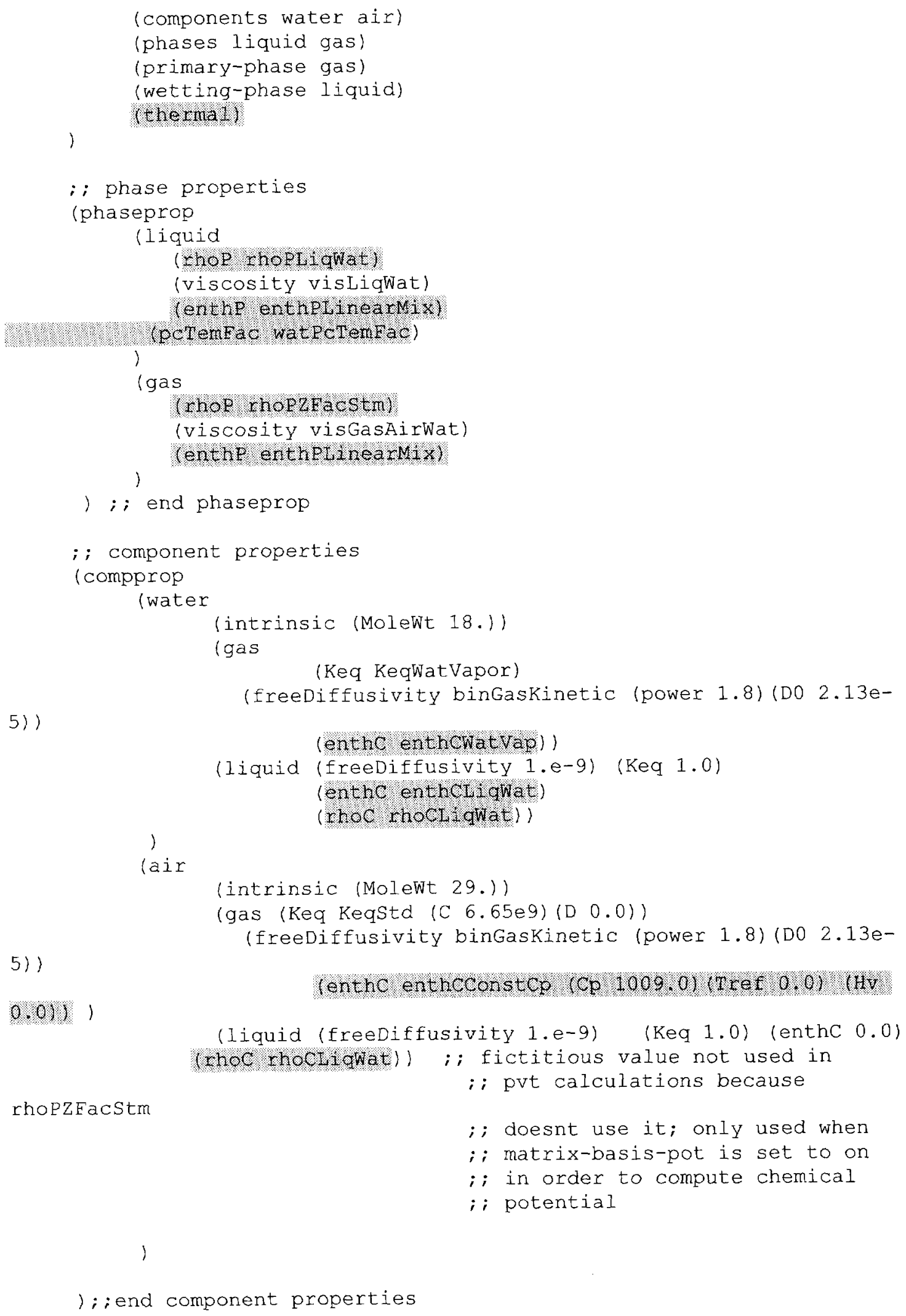

This work was performed under the auspices of the U.S. Department of Energy by the University of California, Lawrence Livermore National Laboratory under Contract No. W-7405-Eng-48. 